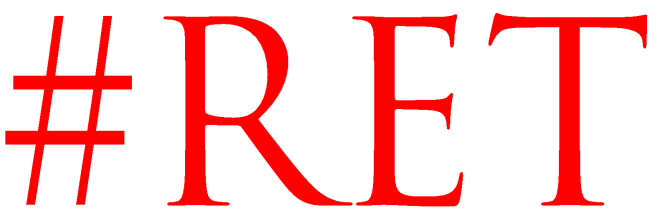

\title{
La incidencia del COVID-19 sobre la transparencia de las instituciones públicas
}

\author{
Miguel Ángel Blanes Climent ${ }^{1}$ \\ Doctor en Derecho \\ Técnico Jurídico del Defensor del Pueblo de la Comunidad Valenciana \\ España

RESUMEN: El artículo se centra en el análisis de los aspectos más destacables con relación a la falta de transparencia durante el Estado de Alarma declarado en marzo de 2020 debido a la crisis del COVID.

PALABRAS CLAVE: COVID, Estado de Alarma, derecho de acceso, datos sanitarios.

CONTENIDOS: 1. Introducción. - 2. El lío con las cifras oficiales. - 3. Ruedas de prensa con preguntas previamente seleccionadas sin publicidad. - 4. La suspensión de los plazos de tramitación de las solicitudes de acceso a la información pública durante el estado de alarma. - 5. La reactivación de los plazos de tramitación de las solicitudes de acceso a la información pública. - 6. El retraso en publicar los contratos de emergencia en el Portal de Transparencia de la Administración General del Estado. - 7. La negativa a facilitar información respecto a la identidad de las personas que forman parte del comité de expertos que asesora al Ministerio de Sanidad. - 8. Algunos consejos para el futuro.

1 Doctor en Derecho y Máster en Derecho Ambiental y Sostenibilidad. Es funcionario de carrera en y actualmente desempeña el puesto de técnico jurídico del Defensor del Pueblo de la Comunidad Valenciana. Twitter: @mablanes - Blog: https://miguelangelblanes.com/ 


\section{The impact of COVID-19 on the transparency of public institutions}

ABSTRACT: The article focuses on the analysis of the most notable aspects in relation to the lack of transparency during the State of Alarm declared in March 2020 due to the COVID crisis.

KEYWORDS: COVID, State of Alarm, right of access, health data. 


\section{Introducción}

La transparencia es necesaria para luchar contra el Covid-19, gobierne quien gobierne. Apunto algunas razones:

- Compartir la información entre todos países y entre todas las entidades territoriales para no cometer los mismos errores. Este virus no conoce fronteras.

- Informar a la ciudadanía para que pueda controlar las decisiones adoptadas por los poderes públicos.

- Luchar contra la desinformación. Son muchas las noticias falsas que circulan estos días por internet y las redes sociales. Esta desinformación genera mucha confusión y angustia a la ciudadanía. La transparencia es el mejor desinfectante contra el virus de los bulos.

\section{El lío con las cifras oficiales}

Nos hemos encontrado con los siguientes problemas: datos básicos pocos fiables, con escasa información desagregada por edades, patologías y sexo de las personas afectadas; diferencias entre los sistemas de recogida de datos entre Comunidades Autónomas y hospitales; descentralización y dispersión de los datos y falta de actualización diaria de los mismos, entre otros.

Se ha echado en falta el funcionamiento coordinado e integrado, en una única página web centralizada, los datos diarios de la expansión del coronavirus, en lugar de tener que ir navegando por las distintas páginas web de los servicios de salud pública autonómicos.

La información no puede facilitarse de cualquier manera, sino de forma desagregada por edades, patologías previas, sexo, etc. para que cada uno de los colectivos afectados la pueda comprender. Además, debería ser publicada de una manera clara, estructurada y entendible para los interesados y, preferiblemente, en formatos reutilizables.

Algunos epidemiólogos entrevistados por los medios de comunicación achacan estos fallos a los diferentes y obsoletos sistemas de gestión estadística entre Comunidades Autónomas, cuyos indicadores no son comparables, así como a la escasa inversión económica y política durante los últimos años para actualizarlos.

La falta de inversión económica y de interés político también fue denunciada en un estudio científico que un grupo de expertos epidemiólogos publicó en 2017. 
También es importante destacar que, nueve años después de la Ley General de Salud Pública de 2011, sí, no me he confundido, he dicho nueve años, todavía no se ha aprobado por el Estado el reglamento necesario para la configuración y funcionamiento de la Red de Vigilancia en Salud Pública, impuesta por el art. 13.3 de dicha Ley.

Esta red es necesaria para coordinar los diferentes sistemas de vigilancia autonómicos, incluyendo entre sus sistemas el de alerta precoz y respuesta rápida, con un funcionamiento continuo e ininterrumpido las veinticuatro horas del día, con el objetivo de centralizar, analizar, interpretar y difundir información para fundamentar las actuaciones de salud pública, velar por un desarrollo homogéneo de la vigilancia en el territorio nacional y crear mecanismos eficaces de coordinación para posibilitar una vigilancia integral.

\section{Ruedas de prensa con preguntas previamente seleccionadas sin publicidad}

Afortunadamente, la presión de la gran mayoria de los medios de comunicación y de la opinión pública, provocaron un cambio en el formato y una mejora en la transparencia de las mismas.

Las ruedas de prensa en un sistema democrático consolidado deben cumplir con los siguientes requisitos mínimos: preguntas libres, sin filtros ni censuras, en directo; respuestas breves, directas y sin evasivas; posibilidad de repreguntar; claridad para facilitar la comprensión y tiempo suficiente.

\section{La suspensión de los plazos de tramitación de las solicitudes de acceso a la información pública durante el estado de alarma}

En mi opinión, es una medida ilegal. La declaración del estado de alarma puede limitar el ejercicio de ciertos derechos fundamentales, pero no suspenderlos, ya que ello es más bien propio del estado de excepción.

Aunque el derecho de acceso a la información pública todavía no ha sido reconocido como un derecho fundamental, cuando se suspende, también se están suspendiendo los siguientes derechos fundamentales: a comunicar o recibir libremente información veraz por cualquier medio de difusión (art. 20.1.d), a participar en los asuntos públicos (art. 23.1) y a acceder a la información pública cuando lo ejercita un cargo electo (concejal, diputado o senador).

El Tribunal Constitucional, en su Sentencia 83/2016, de 28 de abril, ha recordado que la suspensión de derechos fundamentales solo se puede producir durante la declaración de los estados de excepción y sitio, pero no durante el estado de alarma en el que nos encontramos. 
Por un lado, el estado de alarma vacía absolutamente de contenido real el derecho de acceso a la información pública precisamente durante un periodo en el que es muy importante saber lo que está pasando, al margen de la información que se publique de forma activa por parte de las entidades públicas en las páginas webs oficiales. Esta suspensión no tiene ningún sentido en un estado democrático de derecho.

Por otro lado, si el propio Gobierno consideró que las personas que trabajan en los medios de comunicación y en las agencias de noticias de titularidad pública y privada son servicios esenciales en esta crisis del coronavirus (apartado 11 del Anexo del Real Decreto-ley 10/2020, de 29 de marzo), ¿cómo van a desarrollar su trabajo los periodistas si se considera que los plazos de tramitación de las solicitudes del derecho de acceso a la información pública están suspendidos durante el estado de alarma?

Lo lógico sería al revés. No solo que los plazos no estuvieran suspendidos, sino que se hubieran acortado por razones de urgencia para permitir un acceso más rápido a la información por parte de quienes acrediten que trabajan en los medios de comunicación o agencias de noticias, por ejemplo, en un plazo de 5 días, ampliable como máximo a 10. De lo contrario, el interés de la opinión pública en acceder a la información, se retrasa en exceso hasta que desaparece por completo o se reduce considerablemente.

La suspensión ya ha tenido un efecto muy negativo. Ha imposibilitado acceder a la información pública cuándo más falta hacía y más lo exigía la ciudadanía y los medios de comunicación. La forma más efectiva de negar el derecho a la libertad de información es retrasar su ejercicio para ganar tiempo. No es lo mismo denegar el acceso "durante" el estado de alarma, con tantas víctimas mortales y con la opinión pública muy sensible, que denegarlo "después" del estado de alarma, cuando esa negativa puede pasar más desapercibida varios meses o incluso años después. ¿Quién asegura que las resoluciones serán favorables y se entregará la información rápidamente? $Y$ si se deniegan las solicitudes o no se contestan, ¿cuántos meses o años tendrán que pasar para poder acceder a la información tras agotar todas las reclamaciones y recursos judiciales posibles?

Hay que tener en cuenta que este retraso en acceder a la información pública produce mucha desconfianza a la ciudadanía, estimula la proliferación de bulos y noticias falsas y genera mucha indefensión. Si no conoces los informes en que se apoyan las decisiones del Gobierno, es imposible saber si dichas decisiones están justificadas o, por el contrario, son arbitrarias e infundadas. Todo ello incrementa el descontento social y la desafección hacia las instituciones públicas, que no rinden cuentas. 


\section{La reactivación de los plazos de tramitación de las solicitudes de acceso a la información pública}

Con carácter general, se reactivaron con fecha 1 de junio de 2020. No obstante, el apartado 4 de la disposición adicional tercera del Real Decreto 463/2020, por el que se declaró el estado de alarma, permitía que las entidades del sector público pudieran acordar la continuación de aquellos procedimientos administrativos que se refirieran a situaciones estrechamente vinculadas a los hechos justificativos del estado de alarma o que fueran indispensables para la protección del interés general o para el funcionamiento básico de los servicios, como son aquellas solicitudes de información referidas a la gestión del Covid-19.

Al amparo de este apartado 4, algunas entidades públicas sí que continuaron con la tramitación de las solicitudes de acceso a la información pública durante el estado de alarma, pero solo las que voluntariamente quisieron hacerlo.

Los plazos de tramitación de las solicitudes de acceso a la información pública se suspendieron con la declaración del estado de alarma el 14/3/2020.

Como consecuencia de la presión de los medios y la sociedad civil, a mediados de abril, el Ministerio de Política Territorial y Función Pública publicó en el Portal de Transparencia una nota informativa, indicando que las solicitudes se estaban tramitando y que solo se había suspendido la notificación de la resolución estimatoria o desestimatoria. Después, a finales de abril, se publicaron en el mismo portal, sendos informes de la Abogacía del Estado en los que se concluía que, caso a caso, aquellas solicitudes de acceso a la información pública y las reclamaciones ante el Consejo de Transparencia y Buen Gobierno que tuvieran relación con los hechos justificativos de la declaración del estado de alarma o fueran de interés general, se podian seguir tramitando.

\section{El retraso en publicar los contratos de emergencia en el Portal de Transparencia de la Administración General del Estado.}

Conviene destacar que el funcionamiento de los portales de transparencia no fue suspendido por la declaración del estado de alarma. Cuestión distinta es que publicaran con rapidez, y de forma actualizada, toda la información, sobre todo, la más comprometida y sensible.

El Ministerio de Sanidad tardó en publicar los contratos más polémicos, pero al final, se publicaron. La Junta de Consultiva de Contratación Pública del Estado, difundió una nota informativa en la página web del Ministerio de Hacienda, recordando la obligación de publicar todos los contratos, incluidos los de emergencia, tanto en el perfil del contratante, como en los portales de transparencia. 
El problema con la publicación de los contratos de emergencia en los portales de transparencia es que no se tiene la certeza ni la seguridad de que estén todos los adjudicados. Puede ser que se cuelguen algunos para evitar críticas y retrasar u ocultar los que puedan resultar más polémicos.

\section{La negativa a facilitar información respecto a la identidad de las personas que forman parte del comité de expertos que asesora al Ministerio de Sanidad}

El Director del Centro de Coordinación de Alertas y Emergencias Sanitarias, en la rueda de prensa celebrada el día 6/5/2020, se negó a revelar la identidad del equipo de expertos del Ministerio de Sanidad que está asesorando al Gobierno en la aplicación de los criterios que cada territorio tendrá que cumplir para cambiar de fase en la ejecución del plan de desescalada del confinamiento provocado por el coronavirus. La razón dada es evitar la presión social y mediática sobre estos profesionales.

La cuestión es que publicar la identidad de estas personas no es algo voluntario, sino obligatorio. El artículo 11 de la Ley 33/2011, de 4 de octubre. General de Salud Pública, impone la obligación de publicar "la composición de los comités o grupos que evalúen acciones o realicen recomendaciones de salud pública, los procedimientos de selección, la declaración de intereses de los intervinientes, así como los dictámenes y documentos relevantes, salvo las limitaciones previstas por la normativa vigente".

La protección de los datos personales no es obstáculo, puesto que está prevista la cesión sin consentimiento por una norma con rango de Ley.

En la medida en que dichos dictámenes o informes están teniéndose en cuenta para adoptar las decisiones por parte del Ministerio de Sanidad en un sentido o en otro, es decir, forman parte de la motivación de dichas decisiones, no se trataría de informes internos de carácter auxiliar o de apoyo respecto de los cuales el artículo 18.1.b) de la Ley 19/2013, de transparencia, permitiría impedir el acceso a los mismos.

Así pues, hay que publicar su identidad y también sus dictámenes. Se trata de personas que, en su calidad de expertos, y con independencia de su relación jurídica con la Administración (bien sean funcionarios de carrera, interinos, personal eventual o agentes externos), están desempeñando funciones públicas de asesoramiento especial al Ministerio de Sanidad y, por tanto, al Gobierno.

Finalmente, los informes se publicaron, pero todavía no se conoce la identidad de los expertos, ni siquiera sus currículums anonimizados. 
El camino no fue fácil. Hay que recordar que el presidente de la Generalitat Valenciana publicó en la página web de la Consejería de Sanidad el informe enviado al Ministerio y solicitó que el Ministerio hiciera público su informe para conocer cómo se habían aplicado los criterios. No lo consiguió. Al poco tiempo, el Ministerio facilitó al periódico El País el informe que justificaba el mantenimiento en la Fase O de la Comunidad de Madrid, pero seguía sin publicar en el portal de la transparencia los informes relativos a las demás Comunidades Autónomas. El Gobierno dijo que publicaría los informes más adelante, cuando todos los territorios estuvieran en la misma fase. Y, al final, afortunadamente, se publicaron todos los informes.

\section{Algunos consejos para el futuro}

El estado de alarma o las situaciones de emergencia sanitaria no puede ser entendidas como una autorización para suspender $\circ$ restringir derechos fundamentales. Se atribuyen potestades exorbitantes a los poderes públicos, y en la misma medida, la transparencia también debe ser excepcional. Estamos en un Estado Social y Democrático de Derecho que no tiene interrupciones.

No se puede suspender los plazos de tramitación de las solicitudes de acceso a la información pública ni retrasar la publicación de la información en los Portales de Transparencia durante el estado de alarma o la situación de emergencia sanitaria, precisamente cuando más falta hace, en lugar de potenciarlo y facilitar el rápido acceso a la misma, en especial, por parte de los periodistas y medios de comunicación que conforman la opinión pública libre e informada.

Cuanto mayor es la información que se comparte con la ciudadanía, mayor es la confianza hacia las autoridades e instituciones públicas y menor es la alarma social que sufren los ciudadanos por no saber lo que sucede, por no saber la verdad.

Estamos ante una oportunidad inmejorable para mejorar nuestra democracia, haciéndola más justa y transparente, y no la podemos desperdiciar. Hay que aprender de los errores y no volverlos a cometer. Nuestra democracia saldrá ganando, sin duda. 